\title{
Experimental Study of Cavitation and Hydraulic Flip Effects on Liquid Jet Characteristics into Crossflows
}

\author{
N. S. Chemloul \\ Department of Mechanical Engineering ,University Ibn Khaldoun of Tiaret, Algeria \\ Corresponding Author Email: sad_1260@yahoo.fr
}

(Received October 30, 2010; accepted January 10th, 2011)

\begin{abstract}
In this work, the effects of orifice internal flow, such as cavitation and hydraulic flip, on the breakup processes of the liquid jet injected perpendicularly into subsonic crossflows were studied experimentally. To provide several conditions for orifice internal flow, different orifice diameters, injection pressure differentials, and shapes (sharp and round) of the orifice entrance were used. Photographs of liquid flow inside the orifice confirmed the internal flow condition. A stroboscopic light was used to measure the liquid column breakup lengths and the liquid column trajectories. The results showed that the liquid column trajectories in noncavitation flows and cavitation flows had a similar trend, but the liquid column trajectories in hydraulic flip flows had different results because the surface of the liquid in the hydraulic flip flows was detached from the inner wall of the orifice hole. As cavitation bubbles developed inside the sharp-edged orifice, the liquid jet became more turbulent and unsteady. Therefore, the liquid column breakup lengths in the cavitation flows were shorter than those in noncavitation flows. In the hydraulic flip, the breakup lengths had smaller values because the liquid jet diameter was smaller than the orifice diameter, and the acceleration waves occurring on the liquid column spread upstream of the orifice exit, then the breakup process on the liquid jet started from the orifice entrance.
\end{abstract}

Keywords: Internal flow, Cavitation, Hydraulic flip, Liquid jet, Liquid column.

\section{NOMENCLATURE}

\begin{tabular}{|c|c|}
\hline $\begin{array}{l}S \\
C_{c}\end{array}$ & $\begin{array}{l}\text { orifice area } \\
\text { contraction coefficient }\end{array}$ \\
\hline$C_{d}$ & discharge coefficient \\
\hline$d$ & orifice diameter \\
\hline$d_{e q}$ & equivalent diameter of three-dimensional \\
\hline$d_{f}$ & $\begin{array}{l}\text { injector } \\
\text { frontal dimension of three-dimensional }\end{array}$ \\
\hline$d_{j}$ & $\begin{array}{l}\text { injector } \\
\text { jet diameter }\end{array}$ \\
\hline$d_{\text {means }}$ & liquid jet diameter at the nozzle exit \\
\hline$d_{s}$ & $\begin{array}{l}\text { measured from the photographs } \\
\text { streamwise dimension of three dimensional }\end{array}$ \\
\hline & injector \\
\hline$h$ & half-height of planar jet or penetration \\
\hline$L$ & orifice length \\
\hline$m$ & liquid mass flow rate \\
\hline$P_{1}$ & total pressure in the pressure vessel \\
\hline$P_{2}$ & ambient pressure \\
\hline & liquid vapour pressure \\
\hline
\end{tabular}

$q \quad$ liquid /air momentum flux ratio defined by:

$\begin{array}{ll} & \frac{\rho_{f} v_{f}^{2}}{\rho_{a} v_{a}^{2}} \\ U_{a} & \text { air velocity in the test section } \\ U_{f} & \text { liquid velocity at the orifice exit } \\ x & \text { distance in the air stream direction } \\ x_{b} & \text { breakup length in the air stream direction } \\ y & \text { distance in the direction transverse to } \\ & \text { the air stream } \\ y_{b} & \begin{array}{l}\text { breakup length in the direction transverse to } \\ \text { the air stream } \\ y_{t}\end{array} \quad \begin{array}{l}\text { distance to the height point along the } \\ \text { centerline of the spray plume }\end{array}\end{array}$

Greek Symbols

$\Delta P \quad$ liquid injection pressure differential

$\rho_{a} \quad$ air density in the test section

$\rho_{f} \quad$ liquid density

$\alpha \quad$ injection angle

\section{Subscripts}




$\begin{array}{ll}a & \text { air property } \\ b & \text { point of liquid column fracture } \\ c a v & \text { cavitation } \\ \text { eff } & \text { effective value } \\ f & \text { liquid property } \\ \text { hyd } & \text { hydraulic flip }\end{array}$

\section{INTRODUCTION}

For a long time, the liquid jet that is injected perpendicularly into subsonic crossflows and atomized into fine drops by aerodynamic forces has been studied for application in liquid-fueled combustors, such as ramjet engines, scramjet engines, and the afterburner of jet engines. Since the combustion efficiency of these combustors is significantly influenced by the breakup characteristics of the liquid jet, considerable research has been carried out experimentally and analytically on the breakup characteristics of the liquid jet (Schetz et al. (1977), Nguyen et al. (1992), Inamura (2000), Wu et al. (1997), Fuller et al. (2000), Schetz et al. (1980), Ingebo (1984), Inamura et al. (1999)). Generally, the liquid jet (liquid column), breaks up into liquid clumps (ligaments), and a liquid clump disintegrates into finer particles (droplets). The breakup length and the trajectory of the liquid column determine the location of droplets. They are therefore very important parameters for designing an injector and a combustor to optimize combustion efficiency.

Schetz et al. (1977) defined a penetration height as an asymptotic value as the jet lost its normal momentum; they measured the penetration height at 6.25 jet diameters downstream of the center of the injector and expressed it as a function of an injector diameter and a jet / freestream dynamic pressure ratio. Nguyen et al. (1992) proposed the analytical/numerical model that predicted the behavior of nonreacting and reacting liquid jets injected transversely into subsonic crossflows, assuming the jet cross section as an elliptical vortex pair recirculation. Inamura (2000) semitheoretically deduced a simplified equation for the trajectory of a liquid jet traversing subsonic airstreams and compared it with jet-penetration measurements. $\mathrm{Wu}$ et al. (1997) analytically solved the liquid column trajectories on the assumption that liquid acceleration was balanced with aerodynamic drag forces in the airstream direction, and the liquid column could be modeled as a cylindrical fluid element of the diameter of the nozzle exit. The transverse velocity of the liquid column then remained constant to the breakup point. They confirmed these assumptions through experiments and proposed an empirical correlation of the liquid column trajectories consisting of an injector diameter and liquid/air momentum flux ratio. Fuller et al. (2000) investigated the effects of injection angle on the column trajectories in transverse airflows.

Schetz et al. (1980) indicated that the growth of the acceleration wave on the liquid column by aerodynamic force was an important factor of the breakup process. Ingebo (1984) described the waves as capillary and acceleration waves, and explained atomization as a process of forming ligaments from the crest of column waves. Wu et al. (1997) observed that the surface breakup process, as well as the breakup process of the liquid column, took place when the liquid jet momentum was large. They also solved the column fracture location using the time scale for the aerodynamic secondary breakup of a spherical droplet, and confirmed it experimentally. They concluded that the liquid column always broke at a distance of $8.06 \pm$ 1.46 jet diameters downstream of the nozzle. Inamura $e t$ al. (1999) also found that the breakup distance in the airstream direction was not sensitive to the liquid/ air momentum flux ratio and liquid jet properties.

From the results of previous research, it is known that surface tension, or viscosity, does not significantly affect the liquid column trajectory and the breakup length, and aerodynamic force is the most important factor of the breakup process when the liquid jet is not considerably turbulent and cavitation does not occur. As reported by Tamaki et al. (1998) and Wu et al. (1995), however, it is clear that atomization of the liquid jet depends greatly on the disturbance of the liquid flow caused by cavitation inside the orifice, inner surface roughness, etc. Tamaki et al. (1998) found that when the liquid flow was disturbed, caused by increased cavitation inside the orifice, atomization of the liquid jet was considerably promoted and the breakup length became short. However, a study dealing with the effect of orifice internal flows, such as cavitation and hydraulic flip on the liquid jet injected to subsonic crossflows, has not yet been reported. Therefore, the objective of this study is to investigate the effect of orifice internal flows, such as cavitation and hydraulic flip, on the breakup characteristics of transverse injection into subsonic crossflows. The breakup characteristics, such as the breakup length and the trajectory of the liquid jet, which are known to be very important factors in designing an injector and a combustor, were measured by changing orifice diameters, injection pressure differentials, and the shapes (sharp and round) of the orifice entrance.

\section{EXPERIMENT}

\subsection{Experimental Apparatus}

The experimental apparatus consists of flow circuit (Fig.1a) composed of a ring blower (1) for producing air, a settling chamber (2) for stabilizing the air, an air nozzle (3), and a two-dimensional shaped wind tunnel (4). The blower, which could supply a maximum airflow of $0.3 \mathrm{~m}^{3} / \mathrm{s}$, was employed and the settling chamber, sized $0.5 \times 0.5 \times 0.6 \mathrm{~m}$, was used. The stabilized air in the chamber was supplied to the wind tunnel after passing through the air nozzle. As shown in Fig. 1b, the wind tunnel has a rectangular cross section of $50 \times 50 \mathrm{~mm}$ and a length of $330 \mathrm{~mm}$. Visualization windows were built on both sides of the test section for photographing liquid jets, and acrylic windows were installed on the top and bottom walls. The bottom wall has a rectangular hole to permit injectors to be inserted, as shown in Figs. 1b. Air velocity fields in the test section were measured by particle image velocimetry and were fixed to $60 \mathrm{~m} / \mathrm{s}$ on an average due to the maximum capability of the blower (Ahn et al. (2006)). The air temperature was measured by k-type thermocouples 5) in order to calculate the air density in the test section. 
The liquid injection apparatus (Fig.1a) is composed of a pressure vessel (6), a pressure regulator (7), a pressure gauge (8), and an injector (9). The flow rate of the liquid was controlled by a pressure regulator and the pressure vessel was pressurized with high-pressure air. To visualize the internal flow inside the orifice of the injector, the injector was made of an acrylic material, and consisted of the orifice and the internal chamber. For testing noncavitation and cavitation flows, roundedged and sharp-edged orifices were designed, as shown in Figs. 1b and 1c. According to Vennard's results (1961), the orifice entrance is rounded by 0.14 times the orifice diameter or more and has no vena contracta. In order to obtain noncavitation flows, roundedged orifices were designed with a radius of curvature $R$ of one diameter of the orifice. These orifices have a length-to-diameter ratio of 20 . Unlike the round-edged orifice, sharp-edged orifices were designed to obtain cavitation flows and hydraulic flip flows. On the basis of results from Tamaki et al. (1998), sharp-edged orifices, with a length-to-diameter ratio of 20 , and sharp-edged orifices with a length-to-diameter ratio of 5 , were designed to obtain cavitation flows and hydraulic flip flows, respectively. The liquid jets ejecting from the orifice exit were visualized using a digital stroboscope with pulse duration of approximately $10 \mathrm{~ns}$, which could freeze the motion of the liquid column and droplets, and were recorded on a digital camera (Canon EOS D30) with $2160 \times 1440$ pixel array. Photographs were obtained in a darkened room. Since the diameter of the orifice is small, closeup and zoom lenses were used to effectively magnify and record the internal flow of the orifice

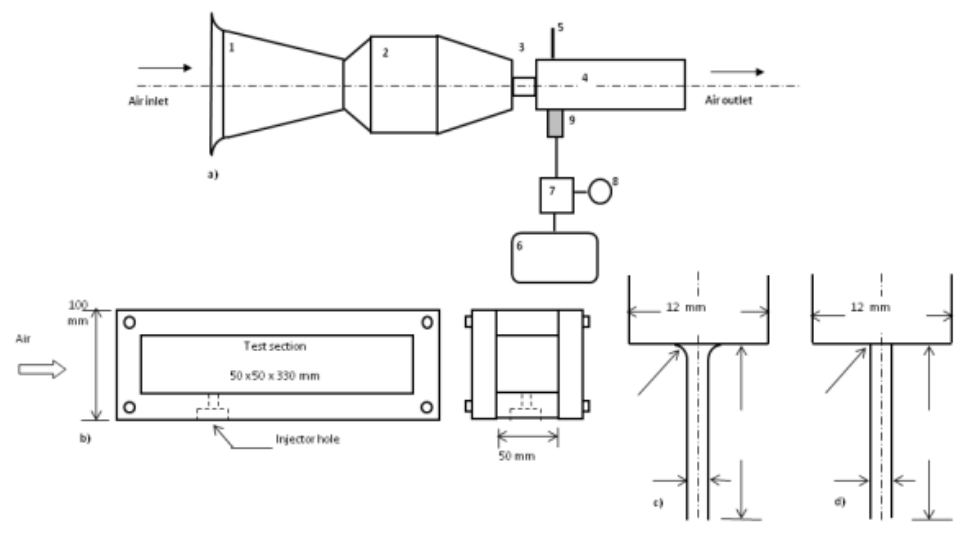

Fig. 1. Experimental apparatus: a) Schematic diagram of the flow circuit : (1) Ring blower, (2) Settling chamber, (3) air nozzle, (4) Wind tunnel, (5) k-type thermocouples, (6) pressure vessel, (7) pressure regulator, (8) pressure gauge,

(9) Injector ; b) test section; c) round-edged orifice; d) sharp- edged orifice; $(R)$ radius of curvature.

\subsection{Test Conditions}

Table 1 shows the dimensions of orifice design parameters and experimental conditions. Orifice diameters were designed as $0.5 \mathrm{~mm}$ and $1.0 \mathrm{~mm}$ for inspecting the effect of the orifice diameter. As previously stated, the round-edged orifice has a lengthto-diameter ratio of 20 in order to induce a more steady flow, and the sharp-edged orifices have length todiameter ratios of 20 and 5 in order to obtain cavitation flows and hydraulic flip flows, respectively. Water was

used as a liquid simulant. The injection pressure differential was varied from 1 to 6 bars to test the visualization of internal flow and jet flow. The differential was varied, as shown in Table 1, to test the liquid column trajectories, due to the size limitations in the test section.

\section{RESUlTS AND DisCUSSION}

\subsection{Flow Characteristics of Liquid Jet}

Table 1 Dimensions of orifice design parameters and experimental conditions

\begin{tabular}{lcccccc}
\hline Orifice & \multicolumn{3}{c}{$0.5 \mathrm{~mm}$} & & $1.0 \mathrm{~mm}$ \\
\hline $\begin{array}{l}\text { Orifice entrance shape } \\
\text { Ratio of orifice length-to-diameter }\end{array}$ & Round & Sharp & Sharp & Round & Sharp & Sharp \\
& 20 & 20 & 5 & 20 & 20 & 5 \\
\hline Experiments & Injection pressure differential, $\Delta P$ (bar) \\
\hline $\begin{array}{l}\text { Visualistion of internal and jet flow } \\
\text { Liquid column trajectory and breakup }\end{array}$ & $1 \sqcup 5$ & $1 \sqcup 6$ & $1 \sqcup 5$ & $1 \sqcup 4$ & $1 \sqcup 5$ & $1 \sqcup 4$ \\
\hline
\end{tabular}

Figure 2 shows the shapes of the orifice internal flow and jet flow as functions of injection pressure differential. For round-edged orifices, there are no significant differences in internal flows; and as the 
injection pressure differential increases, the jet flow tends to have a milky surface, as opposed to the clear glassy appearance of the jet flow at the injection pressure differential of 1 bar (Lefebvre (1989)). For sharp-edged orifices; however, the cavitation phenomenon occurs near the entrance of the orifice, above any critical injection pressure differential; cavitation bubbles are shown as white images in the internal flow photographs. As the injection pressure increases, the cavitation bubbles spread downstream from the entrance and approach the exit of the orifice. Especially in the sharp-edged orifice, with a length-todiameter ratio of 5, cavitation bubbles disappear and the jet flow emerges as a smooth liquid column of a smaller diameter than the orifice diameter because the surface of the liquid flow is detached from the inner wall of the nozzle hole, as Tamaki et al. (1998) mentioned. This phenomenon is called "hydraulic Flip". The difference in liquid jet diameters between noncavitating flow and hydraulic flip flow is so small that it is difficult to detect. Thus, the diameters of the liquid jets ejecting from the orifice exit for the sharp-edged orifices with a length-to-diameter ratio of 5 were measured from the photographs and are shown in Table 2 .

From the photographs of jet flow in Fig. 2, it is observed that cavitation bubbles cause the liquid jet to become turbulent and, as the cavitation bubbles approach the orifice exit, the liquid jet becomes more turbulent and unsteady. According to Lefebvre (1989), if the issuing jet is fully turbulent, the radial velocity component soon causes disruption of the surface film, followed by general disintegration of the jet; no aerodynamic forces are required for breakup. As previously mentioned, in a sharp-edged orifice with a length-to diameter ratio of 5, the liquid jet emerges as a smooth liquid column after cavitation bubbles are ejected from the orifice and disappear within the orifice. The transition process from cavitation to hydraulic flip was explained in detail by Soteriou et al. (1999).

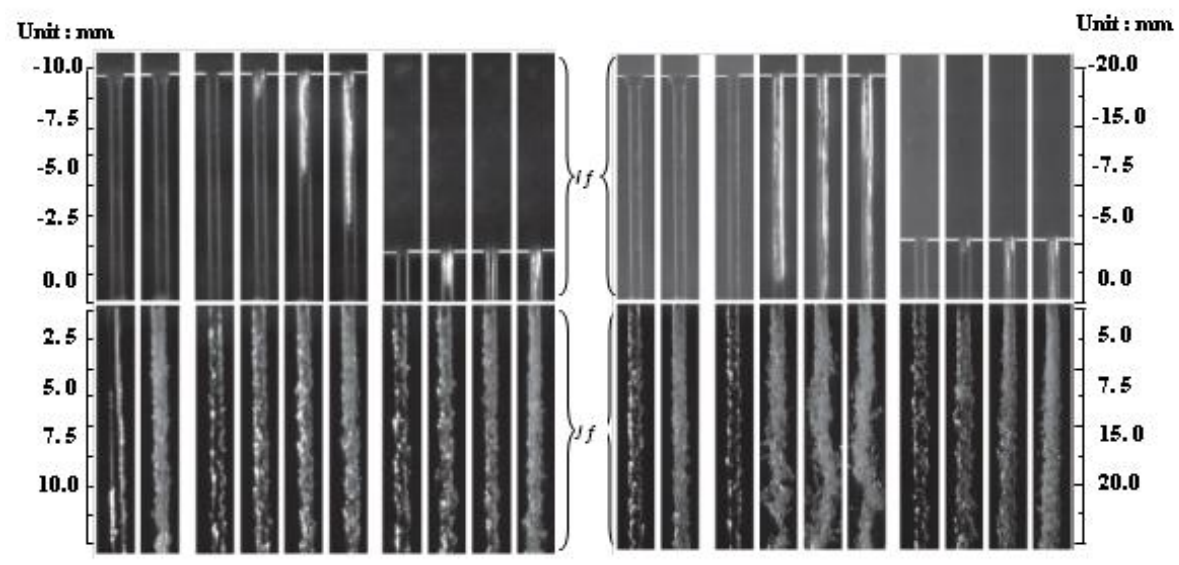

Fig. 2. Visualization of orifice internal flow and jet flow as a function of injection pressure differential: a) $0.5 \mathrm{~mm}$ orifice diameter; b) $1.0 \mathrm{~mm}$ orifice diameter; $(I f)$ : Internal Flow; $(J f)$ : Jet Flow.

Table 2 Diameters of the liquid jets ejecting from the orifice exit for the sharp-edged orifices with a length-todiameter ratio of 5

\begin{tabular}{|c|c|c|c|c|c|c|}
\hline$\triangle P$ (bar) & 1 & 2 & 3 & 4 & 5 & 6 \\
\hline \multicolumn{7}{|c|}{$0.5 \mathrm{~mm}$ orifice diameter } \\
\hline$d_{\text {meas }}$ (Pixels) & 52 & 52 & 48 & 48 & 48 & 48 \\
\hline$d_{\text {meas }} / d$ & 1 & 1 & 0.92 & 0.92 & 0.92 & 0.92 \\
\hline \multicolumn{7}{|c|}{$1.0 \mathrm{~mm}$ orifice diameter } \\
\hline$d_{\text {meas }}$ (Pixels) & 95 & 95 & 88 & 88 & 88 & 88 \\
\hline$d_{\text {meas }} / d$ & 1 & 1 & 0.93 & 0.93 & 0.93 & 0.93 \\
\hline
\end{tabular}

Figure 3 shows the discharge coefficients for roundedged and sharp-edged orifices as a function of injection pressure differential, where the discharge coefficient is calculated using the following equation:

$$
C_{d}=\frac{m}{S \sqrt{2 \rho_{f} \Delta P}}
$$

The discharge coefficients of round-edged orifices are higher than those of sharp-edged orifices. For the round-edged orifice, the discharge coefficient increases slightly and attains a constant value as the injection pressure increases. However, for sharp-edged orifices with a length-to-diameter ratio of 20 , the discharge coefficients in the orifice diameters $(0.5 \mathrm{~mm}$ and 1.0 $\mathrm{mm}$ ) decrease gradually after 4 and 3 bars, respectively, due to the cavitation phenomena. Nurick (1976) found that the discharge coefficient of sharp-edged orifices for the cavitation flows was determined by the following equation:

$C_{d}=C_{c}\left[\left(P_{1}-P_{v}\right) /\left(P_{1}-P_{2}\right)\right]^{0.5}$ 
Schmidt et al. (1977) compared and confirmed this equation with the measurements of other experimentalists. As shown in Figs. 2 and 3, the discharge coefficient of sharp-edged orifices with a length-to-diameter ratio of 20 follows this equation well after cavitation bubbles occur inside the orifice, where the value of $C_{c}$ in the present orifices is calculated as 0.57. On the other hand, the discharge coefficient of sharp-edged orifices with a length-to-diameter ratio of 5 shows not only a gradual drop in the cavitation region, but also a sudden drop in the hydraulic flip region, as shown in Fig. 3. After a sudden drop, the discharge coefficient remains at almost the same value since the surface of the liquid flow is detached from the inner wall of the orifice hole. These relationships between the discharge coefficient and cavitation/hydraulic flip were studied in detail by Soteriou et al. (1995).
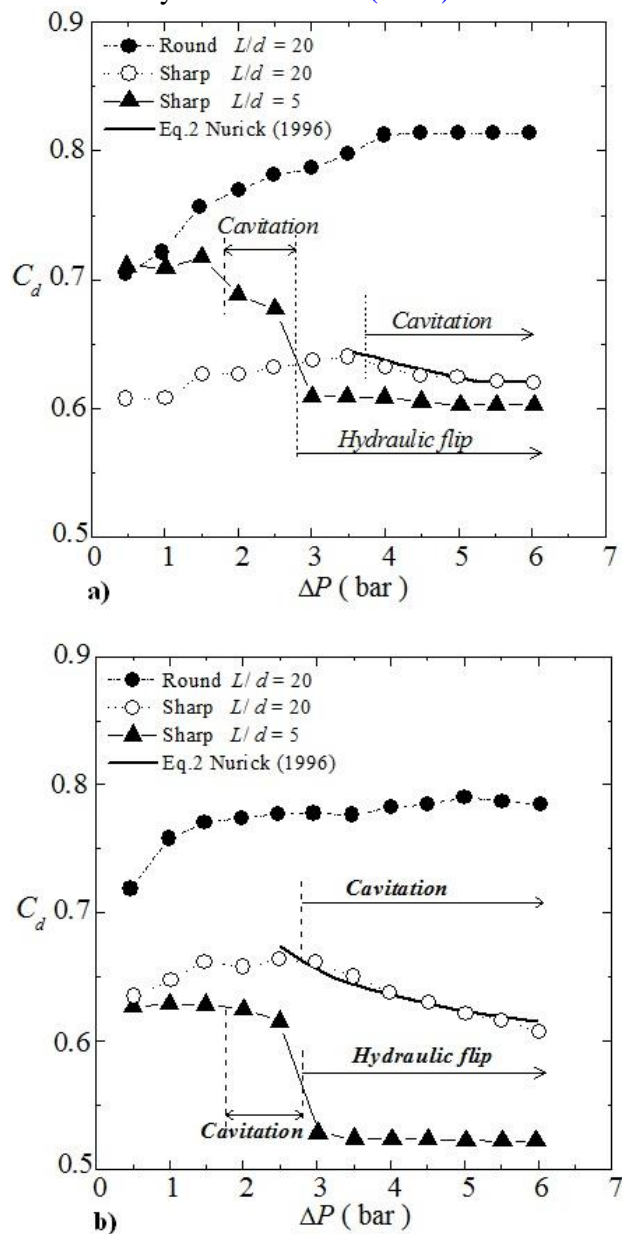

Fig. 3. Discharge coefficients for round-edged and sharp-edged orifices as a function of injection pressure differential: a) $0.5 \mathrm{~mm}$ orifice diameter; b) $1.0 \mathrm{~mm}$ orifice diameter.

\subsection{Liquid Column Trajectories}

Figure 4 shows a schematic of the jet structure and breakup process of transverse injection. As Wu et al. (1997) reported, the liquid jet may first undergo surface breakup with droplets stripped from the liquid surfaces when the liquid/air momentum flux ratio is high. Acceleration waves grow, and the liquid column deforms and is flattened due to aerodynamic drag force. The flattening of the liquid column also causes aerodynamic drag forces to increase significantly because of the increase in the frontal projected area. The liquid column then disintegrates into ligaments and droplets. The breakup lengths are defined as the distance from the center of the orifice exit to the point of the liquid column fracture, as shown in Fig. 4.

Liquid column trajectories were measured from the images obtained using a stroboscopic light; points on the upper and lower surfaces of the liquid column were detected by the difference in intensity, using an inhouse code. The line connecting the mean value of the upper point and the lower point was defined as the liquid column trajectory. Liquid column trajectories were measured with an interval of $0.2 \mathrm{~mm}$ from the half-diameter of the orifice exit in the airstream to the liquid column fracture point. In order to obtain the mean trajectory of the liquid column, values acquired from 100 instantaneous images were averaged for each case.

\subsubsection{Noncavitation Flow}

Trajectories of a liquid jet transversely injected into crossflows have been studied by numerous researchers. From previous research, it is known that orifice diameter and the liquid/air momentum flux ratio are the most important parameters for the trajectories. Schetz (1980) obtained the complete formula, including the influence of $q$, the aspect ratio $\left(d_{f} / d_{s}\right)$ of the injector, and injection angle $\alpha$ as follows:

$$
\begin{gathered}
\frac{h}{d_{j}}=1.32(q)^{0.5} C_{d}\left(\frac{d_{e q}}{d_{f}}\right)^{2}\left(\frac{d_{f}}{d_{s}}\right)^{0.46} \\
\mathrm{x} \ln \left[1+6\left(\frac{x}{d_{j}}\right)\right] \sin \left(\frac{2 \alpha}{3}\right)
\end{gathered}
$$

Assuming that the liquid acceleration was balanced with aerodynamic drag forces and that the liquid column could be modelled as a cylindrical fluid element of the diameter of the nozzle exit, Wu et al. (1997) represented the correlation of the liquid column trajectory before the fracture point as follows:

$\frac{y}{d}=1.37 \sqrt{q \frac{x}{d}}$

Wu et al. (1998) then proposed the correlation of the spray penetration in the spray plumes as follows:

$\frac{y_{t}}{d}=4.3\left(q \frac{x}{d}\right)^{0.33}$

The differences between these correlations are believed to be due to the experimental conditions and the length at which the trajectory was measured. Because the present research is focused on the liquid jet before the column fracture point, Eq. (4) will be used to compare the present results. 


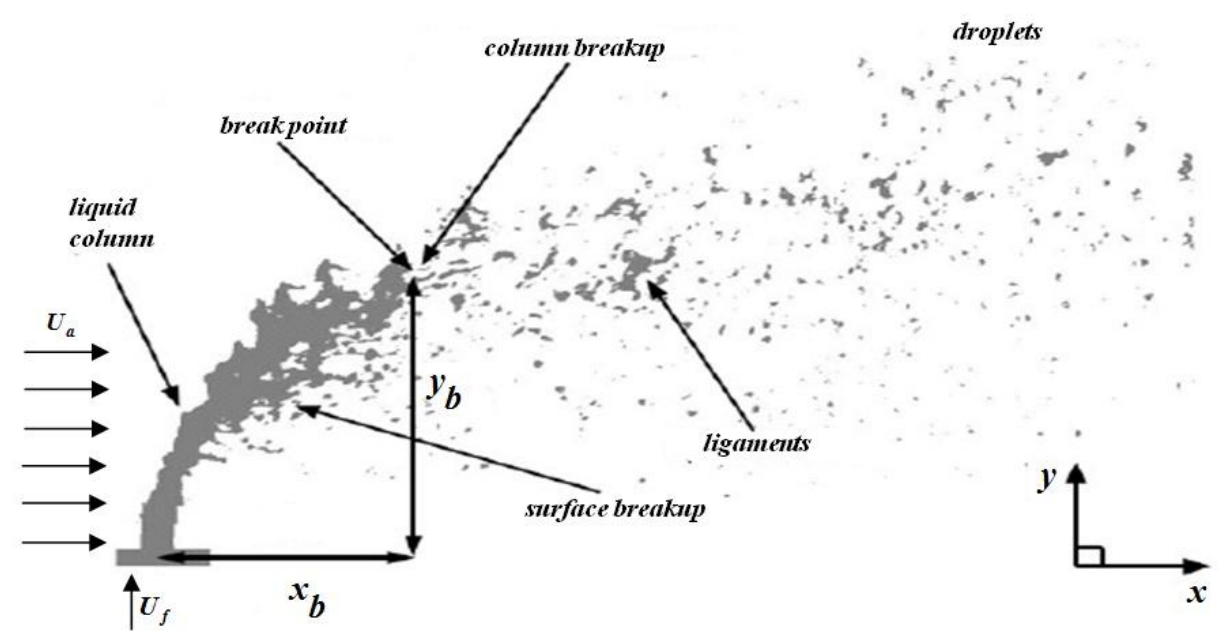

Fig. 4. Jet structure and breakup process of transverse injection

Figure 5 shows the liquid column trajectories normalized by the orifice diameter, and the liquid/air momentum flux ratio for the round-edged orifices, where injection jet velocities were calculated from the following equation:

$U_{f}=C_{d} \sqrt{2 \frac{\Delta P}{\rho_{f}}}$

As the orifice diameter or liquid/air momentum flux ratio increased, the liquid jet penetrated higher. From the results, an empirical correlation for the trajectory in the round-edged orifices could be obtained as follows:

$\frac{y_{t}}{d_{q}}=1.297\left(\frac{x}{d_{q}}\right)^{0.509}$

This empirical equation has an only slightly smaller constant $(\sim 5 \%)$ than Eq. (4) of Wu et al. (1997) because they defined the liquid column location as the points on the upper surface of the liquid column.

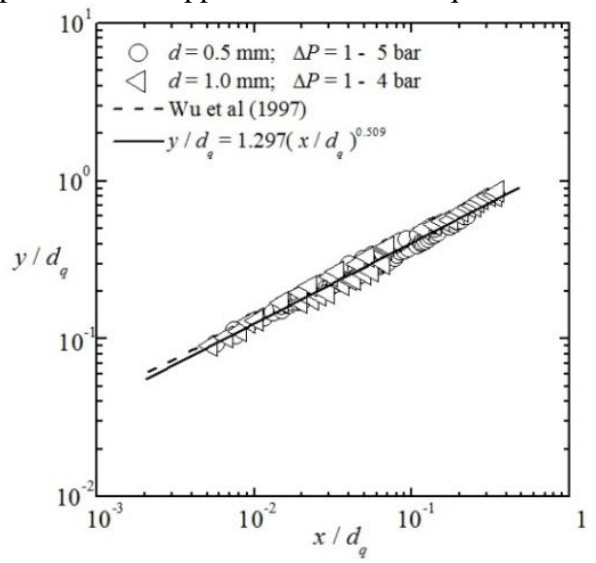

Fig. 5. Liquid column trajectories normalized by orifice diameter $d$ and liquid/air momentum flux ratio $q$ for round-edged orifices

\subsubsection{Cavitation Flow}

When cavitation bubbles occur in the orifice entrance, it is difficult to define the velocity and area of the liquid ejecting from the orifice because it includes bubbles, and because the density of the liquid jet decreases. By extending the one dimensional model to the exit of orifice, Schmidt et al. (1977) resolved the problem of effective jet velocity and effective jet diameter in cavitation flows as follows:

$$
\begin{aligned}
U_{e f f, c a v} & =\frac{2 C_{c} P_{1}-P_{2}+\left(1-2 C_{c}\right) P_{v}}{C_{c} \sqrt{2 \rho_{f}\left(P_{1}-P_{v}\right)}} \\
S_{\text {eff,cav }} & =\frac{2 C_{c}^{2}\left(P_{1}-P_{v}\right)}{2 C_{c} P_{1}-P_{2}+\left(1-2 C_{c}\right) P_{v}} S
\end{aligned}
$$

Table 3 represents the values of $U_{f}, U_{\text {eff,cav }}$ and $\left(S_{\text {eff,cav }} / S\right)$ for sharp-edged orifices with a length to diameter ratio of 20 , where $C_{c}$ is calculated as 0.57 from Fig. 3 The effective velocities are approximately $50 \%$ greater than the velocities defined by Eq. (6). To determine whether Eq. (6) or Eq. (8) is more accurate for normalizing the liquid column trajectories in the case of cavitation flows, the normalized liquid column trajectories for cavitation flows are plotted in Fig. 6, where $d_{\text {eff,cav }}$ and $q_{\text {eff,cav }}$ are calculated from Eqs. (8) and (9).

The trajectories of the liquid column in Fig. 6a follow well the empirical correlation of Eq. (7), acquired from the round-edged orifices. On the other hand, the trajectories of the liquid column in Fig. $6 \mathrm{~b}$ show a significant difference from Eq. (7) Consequently, the velocity that is defined by Eq. (6) and the orifice diameter are more appropriate for normalizing the liquid column trajectories for cavitation flows. In the case of cavitation flows, the surface of the liquid is not detached from the inner wall of the orifice hole. As Schmidt et al. (1977) mentioned, their model can be applied only at high injection pressure and moderate values of $L / d$. In our experiments, the injection pressure is not high compared to their work. Therefore, $d_{\text {eff,cav }}$ and $q_{\text {eff,cav }}$, acquired from the assumptions of Schmidt et al. (1977), are believed to be inappropriate for normalizing the liquid column trajectories. 
Table 3 Velocity and area of the liquid jet for the sharpedged orifices with a length-to-diameter ratio of 20

\begin{tabular}{llrl}
\hline$\Delta P(\mathrm{bar})$ & $U_{f}(\mathrm{~m} / \mathrm{s})$ & $U_{\text {efficav }}$ & $S_{\text {eff,cav }} / S$ \\
\hline \multicolumn{4}{c}{$0.5 \mathrm{~mm}$ orifice diameter } \\
\hline 4.0 & 17.91 & 26.07 & 0.96 \\
5.0 & 19.69 & 29.58 & 0.67 \\
6.0 & 21.40 & 32.73 & 0.65 \\
\hline \multicolumn{5}{c}{} \\
\hline 3.0 & $1.0 \mathrm{~mm}$ orifice diameter \\
4.0 & 16.20 & 22.08 & 0.73 \\
5.0 & 18.04 & 26.07 & 0.69 \\
& 19.71 & 29.58 & 0.67 \\
\hline
\end{tabular}

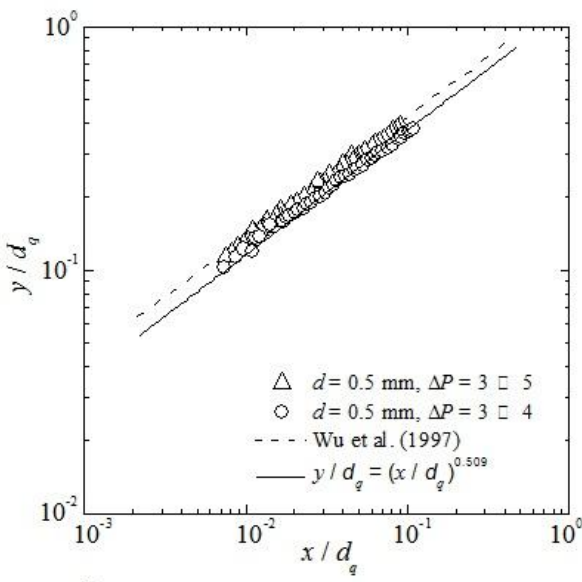

a)

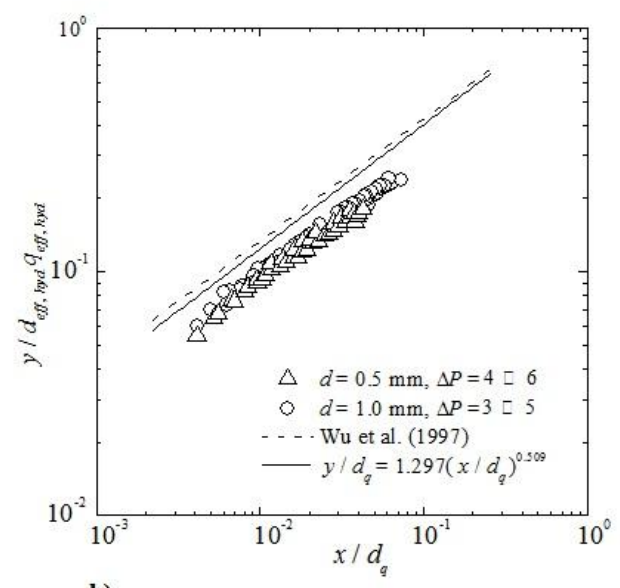

b)

Fig. 6. Liquid column trajectories for cavitation flows normalized by: a) orifice diameter and liquid/air momentum flux ratio; b) effective jet diameter and effective liquid/air momentum flux ratio

\subsection{Hydraulic Flip Flow}

During hydraulic flip, the surface of the liquid flow is detached from the inner wall of the orifice hole so that the area of the liquid flow becomes smaller than the orifice diameter. Hence, it is evident that the velocity obtained from Eq. (6) and the orifice diameters are not appropriate for normalizing the liquid column trajectories. But Eqs. (8) and (9), which assume that cavitation bubbles occur at the orifice entrance, also cannot be applied to this phenomenon. The friction loss inside the orifice is believed to be negligible since the length of the orifice is much smaller than the distance between the pressure vessel and the injector. From Fig. 3, Eqs. (1) and (6), it can be assumed that the discharge coefficients represent the area of the liquid jet. In other words, the sudden decrease of the discharge coefficient for hydraulic flip flows, as shown in Fig. 3, is believed to indicate the decrease of the area of the liquid jet. Therefore, the effective velocity and effective area of the liquid jet during hydraulic flip are defined as follows:

$$
\begin{aligned}
& S_{\text {eff, hyd }}=\frac{2 C_{d, \text { hyd }}}{C_{d, \text { non }}} S \\
& U_{\text {eff, hyd }}=U_{f} \frac{S}{S_{\text {eff, hyd }}}
\end{aligned}
$$

Where $C_{d, n o n}$ is set to be the maximum discharge coefficient in noncavitation conditions.

Table 4 represents the values of $U_{f}, U_{\text {eff, hyd }}$ and $\left(S_{\text {eff, hyd }} / S\right)$ for sharp-edged orifices with a length-todiameter ratio of 5 . Comparing these values with the values in Table 2, it is confirmed that the ratio of the effective area of the liquid jet acquired from Eq. (10) to the orifice area is almost the same as the ratio of the area measured directly from the photograph to the orifice area. As shown in Table 4, $\left(S_{\text {eff, hyd }} / S\right)$ is almost constant because the ratio between the area of a vena contracta and the area of an orifice usually depends on the shape of the orifice edge above any critical pressure differential, and the divergence of the fluid beyond the vena contracta is quite small. The values of the effective velocities are approximately $20 \%$ greater than the values of the velocities obtained from Eq. (6). To determine whether Eq. (6) or Eq. (11) is more accurate for normalizing the liquid column trajectories during hydraulic flip flows, the normalized liquid column trajectories for hydraulic flip flows are plotted in Fig. 7, where $d_{\text {eff, hyd }}$ and $q_{\text {eff, hyd }}$ are calculated from Eqs. (10) and (11).

Table 4 Velocity and area of the liquid jet for the sharpedged orifices with a length-to-diameter ratio of 5

\begin{tabular}{llll}
\hline$\Delta P$ (bar) & $U_{f}(\mathrm{~m} / \mathrm{s})$ & $U_{\text {eff hyd }}$ & $S_{\text {eff hyd }} / S$ \\
\hline \multicolumn{4}{c}{$0.5 \mathrm{~mm}$ orifice diameter } \\
\hline 3.0 & 14.91 & 17.57 & 0.85 \\
4.0 & 17.18 & 20.28 & 0.85 \\
6.0 & 19.04 & 22.68 & 0.84 \\
\hline \multicolumn{4}{r}{} \\
\hline 3.0 & $1.0 \mathrm{~mm}$ orifice diameter \\
4.0 & 12.97 & 15.40 & 0.84 \\
\hline
\end{tabular}

The trajectories of the liquid column in Fig. 7a show a significant difference from Eq. (7). On the other hand, 
the trajectories of the liquid column in Fig. $7 \mathrm{~b}$ follow well the empirical correlation of Eq. (7), acquired from the round-edged orifices. Consequently, it is determined that velocity and area, defined by Eqs.(10) and (11), are more appropriate for normalizing the liquid column trajectories in hydraulic flip flows-and thus the velocity and area of the liquid jet ejecting from the orifice during hydraulic flip - can be obtained from Eqs. (10) and (11).

\subsection{Liquid Column Breakup}

\subsubsection{Flow Visualization}

Figure 8 shows the breakup patterns of water jets according to the conditions of orifice internal flows: (a) noncavitation flow, (b) hydraulic flip flow, and (c, d) cavitation flows. The water jets in Figs. $8 \mathrm{a}$ and $8 \mathrm{~b}$ have a similar breakup process. The liquid jet undergoes surface breakup and the acceleration wave grows. Then the liquid column deforms and disintegrates into ligaments and droplets. Fuller et al. (2000) reported that the growth of the acceleration wave on the liquid column by the aerodynamic force was an important part of the breakup process. However, for cavitation flows, the water jets in Figs. $8 \mathrm{c}$ and $8 \mathrm{~d}$ represent a very active breakup process since the cavitation bubbles cause the liquid jet to become turbulent and unsteady. Hence, the breakup length of the liquid column becomes short. Tamaki et al. (1998) measured the vibration acceleration associated with the disturbance in the nozzle hole using a piezoelectric acceleration transducer. They determined that the primary factor in the breakup process of the liquid jet was the disturbance of the liquid flow, caused by cavitation. They found that at this time, atomization of the liquid jet was considerably promoted and the breakup length became short.

At the height of the orifice diameter $\mathrm{d}$ from the orifice exit, the diameters of the liquid column in Figs. $8 \mathrm{c}$ and $8 \mathrm{~d}$ are approximately $10 \%$ larger than that in Fig. 8a because during cavitation, the liquid jet has a relatively large radial velocity (Soteriou et al. (1999)).

On the other hand, the diameter of the liquid column in Fig. $8 \mathrm{~b}$ is approximately $8 \%$ smaller than that in Fig. $8 \mathrm{a}$ because the surface of the liquid flow is detached from the inner wall for hydraulic flip flows.

The surface breakup occurs more violently in Figs. $8 \mathrm{c}$ and $8 \mathrm{~d}$ because turbulent eddies on the surface of the liquid column take place easily and are quickly amplified by the disturbance of the liquid turbulence (Lefebvre (1989)). Hence, the water jets in Figs. 8c and $8 \mathrm{~d}$ show much broader spray plumes than those in Figs. $8 \mathrm{a}$ and $8 \mathrm{~b}$, and have unsteady breakup characteristics. Therefore, when the liquid flow, with cavitation inside the orifice, is injected transversely into subsonic crossflows, the disturbance of the liquid flow, caused by cavitation, is believed to be a more important factor for breakup than the acceleration wave on the liquid column by aerodynamic force.
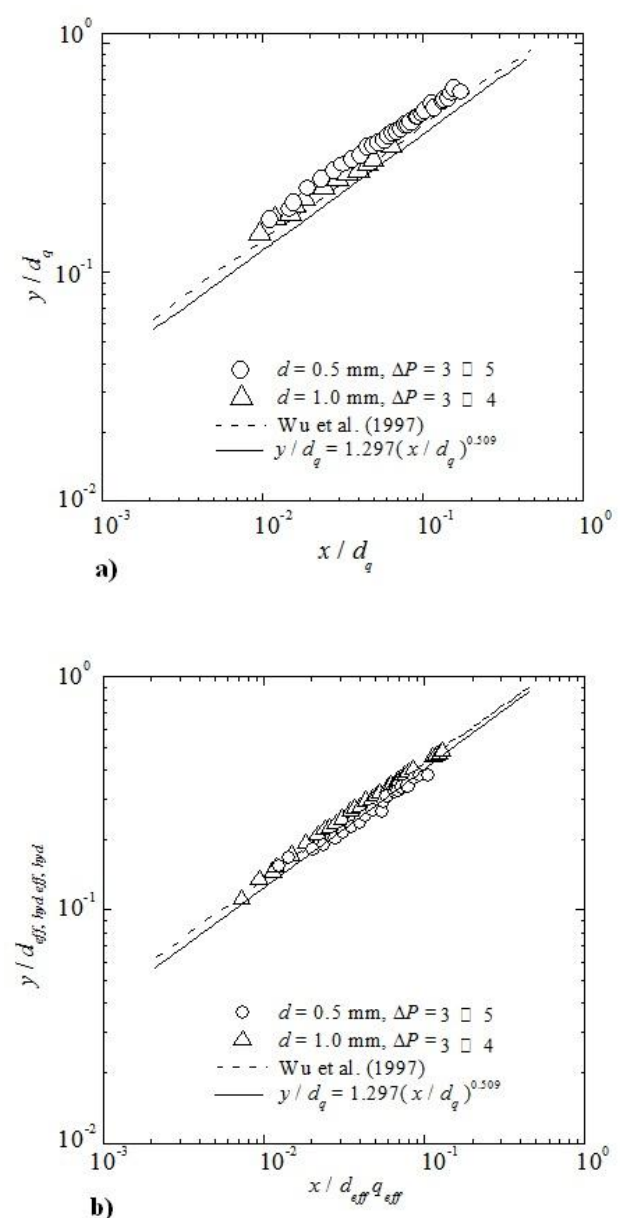

Fig. 7. Liquid column trajectories for hydraulic flip flows normalized by: a) orifice diameter and liquid/air momentum flux ratio; b) effective jet diameter and effective liquid/air momentum flux ratio

\subsubsection{Breakup Locations}

Like liquid column trajectories, breakup locations were measured using an in-house code. However, the code sometimes recognized ligaments as liquid columns because there were often big ligaments after column breakup, as shown in Fig. 4. Therefore, breakup locations were measured manually from the photographs. In order to obtain mean breakup lengths, values acquired from 100 instantaneous images were averaged for each case.

Figure 9 shows the x-directional column breakup lengths of the liquid jet according to the condition of the internal flow. For noncavitation flows, the liquid jet has an approximate breakup length of $x_{b} / d=8.02 \pm 1.43$ -irrespective of injection pressure differential or liquid/air momentum flux ratio- as Wu et al. (1997) reported. On the other hand, in cavitation flows, the liquid jet has a shorter breakup length as injection pressure differential increases. For cavitation flows, as shown in Figs. 2 and 8, as injection pressure differential increases, cavitation develops and the liquid jet becomes turbulent; then the breakup length of the liquid jet becomes shorter. The normalized breakup lengths in the orifice of $d=1.0 \mathrm{~mm}$ are smaller than those in the orifice of $d=0.5 \mathrm{~mm}$ because cavitation takes place 
more seriously and the liquid jets ejecting from the orifice are more turbulent in the orifice of $d=1.0 \mathrm{~mm}$, as shown in Fig. 2. For hydraulic flip flows, the internal flow and the diameter of the liquid jet becomes smaller than the orifice diameter. Hence, the liquid jet has a detaches from the inner surface of the orifice hole, smaller breakup length than $x_{b} / d=8.02$. However, the breakup length normalized by $d_{\text {eff, hyd }}$ also has a smaller value than the anticipated $x_{b} / d_{\text {eff, }, \text { yd }}=8.02$, as shown in Fig. 9c. It is believed that, since the liquid jet during hydraulic flip detaches from the inner surface of the orifice, the acceleration waves occurring on the liquid column spread upstream of the orifice exit; then the breakup process on the liquid jet starts from the orifice entrance. This phenomenon can be also

a)
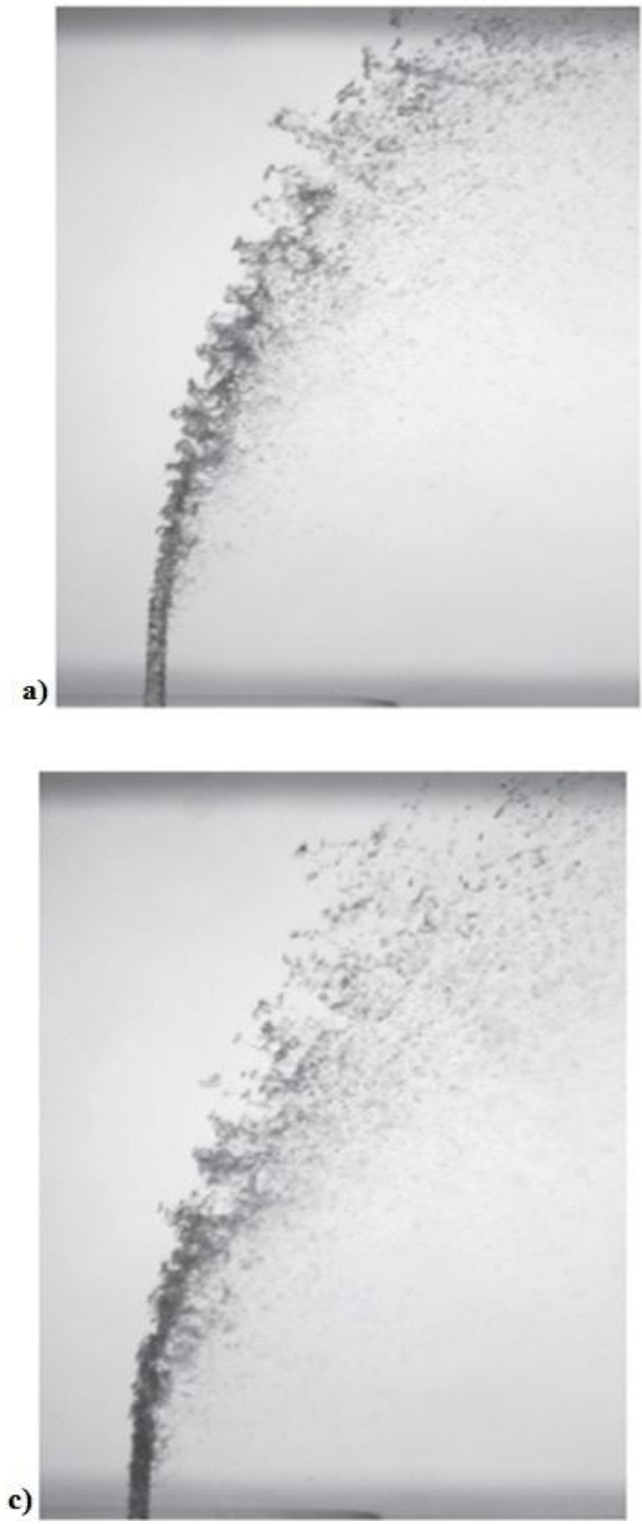

confirmed in Fig. 8b. The liquid jet in Fig. 8b shows acceleration waves earlier than the liquid jet in Fig. 8a

Figure 10 shows the y-directional column breakup lengths of the liquid jet, according to the condition of the internal flow. For noncavitation flows, the breakup length of the liquid jet follows well the result $y_{b} / d=3.44 q^{0.5}$ of $\mathrm{Wu}$ et al. (1997). On the other. hand, for cavitation flows, the breakup length has a smaller value, similar to the x-directional breakup length in Fig. 9b. For hydraulic flip flows, the breakup length is expressed by the effective jet diameter and effective liquid/air momentum flux ratio, and the breakup length also has a slightly smaller value. Since the breakup length in hydraulic flip flows is normalized by $d_{\text {eff, hyd }}$, the difference from the value of $\mathrm{Wu}$ et al. (1997) is not great.

b)

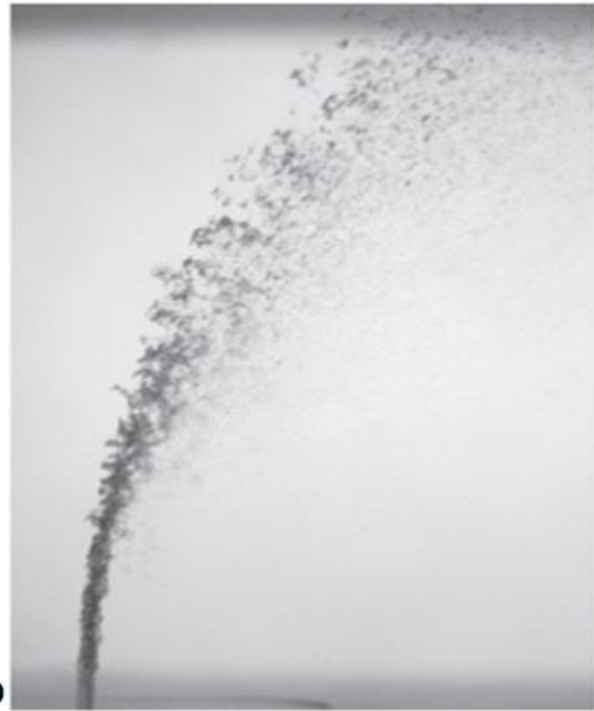

d)

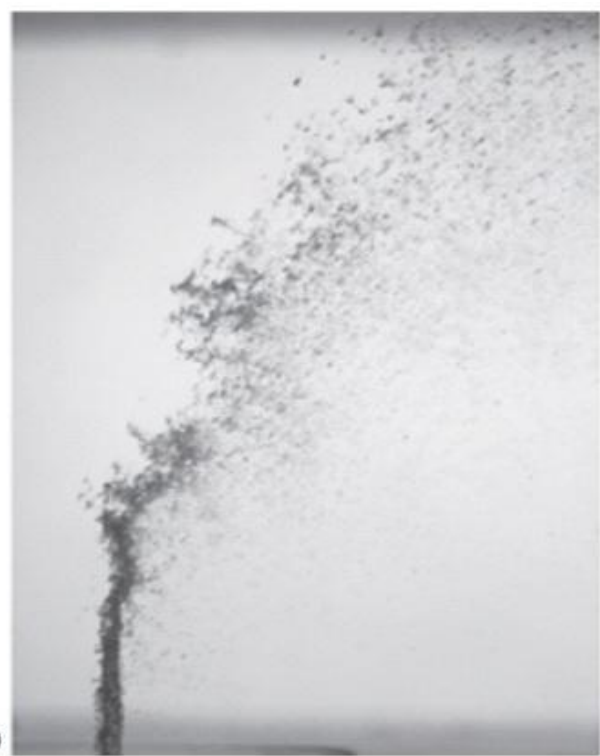

Fig. 8. Liquid column breakup patterns $(d=1.0 \mathrm{~mm})$ : a) noncavitation flow in the round-edged orifice with $\Delta \boldsymbol{P}=3$ bar; b) hydraulic flip flow in the sharp-edged orifice with a length-to-diameter ratio of 20 and $\Delta \boldsymbol{P}=4$ bar; $\mathbf{c}$ ) and d) cavitation flow in the sharp-edged orifice with a length-to-diameter ratio of 5 and $\Delta \boldsymbol{P}=4$ bar 

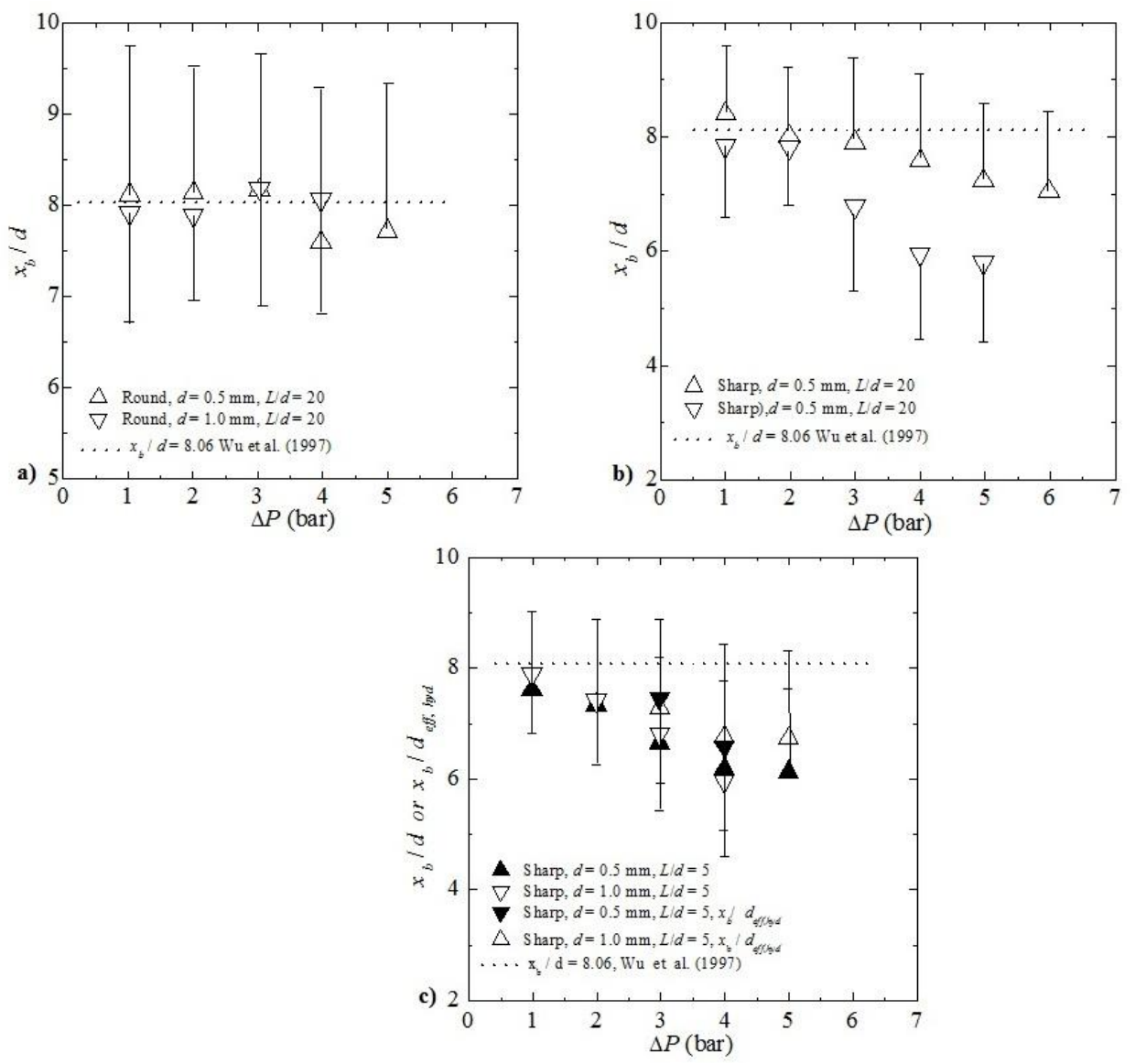

Fig. 9. Breakup lengths in the $\mathrm{x}$-direction with injection pressure differential: a) round-edged orifices with a length to diameter ratio of 20 ; b) sharp-edged orifices with a length-to-diameter ratio of 20; c) sharp-edged orifices with a length-to-diameter ratio of 5

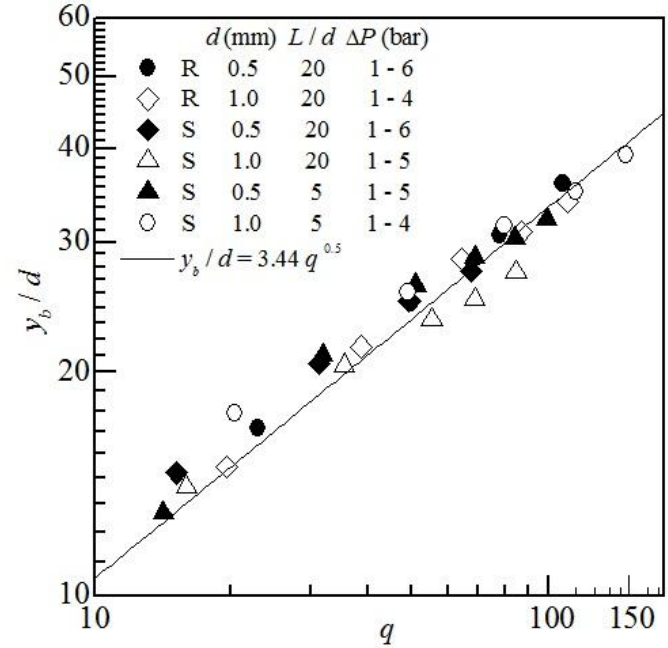

Fig. 10. Breakup lengths in the $y$-direction with liquid/air momentum flux ratio: $(\mathrm{R})$ round-edged orifices, (S) sharp-edged orifices

\section{CONCLuSion}

From the experiments on the effects of orifice internal flow, such as cavitation and hydraulic flip on the liquid column trajectories, and the breakup lengths of transverse injection into subsonic crossflows, the following conclusions could be drawn:
- For sharp-edged orifices with a length-to-diameter ratio of 20 , the discharge coefficients decrease gradually as cavitation bubbles develop. On the other hand, for sharp-edged orifices with a length-to-diameter ratio of 5, the discharge coefficients decrease gradually in the cavitation region, drop suddenly in the hydraulic flip region, and then remain with almost the same values.

- For noncavitation flows and cavitation flows, the liquid column trajectories that are normalized by the orifice diameter and liquid/air momentum ratio, using Eq. (6), follow well the correlation of Wu et al. (1997), because the surface of the liquid flow is not detached from the inner wall of the orifice hole. However, for hydraulic flip flows, the surface of the liquid flow is detached from the inner wall, so that the liquid column trajectories, normalized by the orifice diameter and liquid/air momentum ratio using Eq. (6), show larger differences from the correlation of Wu et al. (1997). Therefore, it is believed that the diameter and the liquid/air momentum ratio obtained from Eqs. (10) and (11) are more appropriate for normalizing the liquid column trajectories during hydraulic flip flows.

- For noncavitation flows, the liquid jet has an approximate breakup length of $x_{b} / d=8.02 \pm 1.43$, irrespective of the injection pressure differential or liquid/air momentum flux ratio, as Wu et al. (1997) reported. On the other hand, for cavitation flows, the 
liquid jet has a shorter breakup length as injection pressure differential increases. As injection pressure differential increases, cavitation develops and the liquid jet becomes turbulent; then the breakup length of the liquid jet becomes shorter.

- For hydraulic flip flows, the internal flow detaches from the inner surface of the orifice hole and the diameter of the liquid jet becomes smaller than the orifice diameter. However, the breakup length normalized by $d_{\text {eff, hyd }}$ has a smaller value than the anticipated $x_{b} / d_{\text {eff, } h y d}=8.02$. It is believed that, since the liquid jet during hydraulic flip detaches from the inner surface of the orifice, the acceleration waves occurring on the liquid column spread upstream of the orifice exit; then the breakup process on the liquid jet starts from the orifice entrance.

\section{ACKNOWLEDGEMENTS}

This work has been supported by Research Laboratory of Industrial Technologies, University Ibn Khaldoun of Tiaret.

\section{REFERENCES}

Ahn, K., Y. Yoon (2006). Experimental Study on the lowfields in a Side-Dump Combustor Using Particle Image Velocimetry, Journal of Propulsion Power, 16, 15- 34.

Fuller, R.P., P.K. Wu, K.A. Kirkendall and A.S. Nejad (2000). Effects of Injection Angle on Atomization of Liquid Jets in Transverse Airflow. AIAA Journal, 38, 64-72.

Inamura, T., N. Nagai, T. Watanabe and N. Yatsuyanagi (1999). Disintegration of Liquid and Slurry Jets Traversing Subsonic Airstreams. Experimental Heat transfer, Fluid Mechanics and Thermodynamics. In Kelleher MD, Shah RK, Sreenivasan KR, Joshi Y., editors, Elsevier, Amsterdam, 1522-1529.

Inamura, T. (2000). Trajectory of a Liquid Jet Traversing Subsonic Airstreams. Journal of Propusionl Power 2000, 16, 155-157.

Ingebo, R.D. (1984). Aerodynamic Effects of Combustor Inlet-Air Pressure on Fuel Jet Atomization. AIAA Paper 84-1320.

Lefebvre, A.H. (1989). Atomization and Sprays, In Hemisphere Publication Corporation, Philadelphia; Chapter 2.
Nurick, W.H. (1976). Orifice Cavitation and its Effect on Spray Mixing. Journal of Fluids Engineering, 98, 681-687.

Nguyen, T.T. and A.R. Karagozian (1992). Liquid Fuel Jet in Subsonic Crossflow, Journal of Propulsion Power, 8, 21-29.

Schetz, J.A., E.A. Kush and P.B. Joshi PB (1980). Wave Phenomena in Liquid Jet Breakup in a Supersonic Crossflow. AIAA Journal, 18, 774-778.

Schetz, J.A. (1980). Injection and Mixing in Turbulent Flow. Progress in Astronautics and Aeronautics, Summerfield ed., AIAA, New York.

Schetz, J.A. and A. Padhye (1977). Penetration and Breakup of Liquids in Subsonic Airstreams. AIAA Journal, 15, 1385-1390.

Schmidt, D.P. and M.L. Corradini (1977). Analytical Prediction of the Exit Flow of Cavitating Orifices., Atomization and Sprays Journal, 7, 603-616.

Soteriou, C. and R. Andrews (1995). Smith M. Direct Injection Diesel Sprays and the Effect of Cavitation and Hydraulic Flip on Atomization, SAE Paper no. 950080.

Soteriou, C., R. Andrews and M. Smith (1999). Further Studies of Cavitation and Atomization in Diesel Injection, SAE Technical Paper Series, 0, 1486.

Tamaki, N., M. Shimizu, K. Nishida and H. Hiroyasu (1998). Effects of cavitation and internal flow on atomization of a Liquid Jet", Atomization and Sprays Journal, 8, 179-197.

Vennard, J.K. (1961). Elementary fluid mechanics, Wiley Editor, New York

Wu, O.P.K., R.F. Miranda and G.M. Faeth (1995). Effects of Initial Flow Conditions on Primary Breakup of Nonturbulent and Turbulent Round Liquid Jets, Atomization and Sprays Journal, 5, 175-196.

Wu, P.K., K.A. Kirkendall, R. Fuller and A.S. Nejad (1997). Breakup Processes of Liquid Jets in Subsonic Crossflows, Journal of Propulsion Power, 13, 64-73.

Wu, P.K., K.A. Kirkendall, R.P. Fuller and A.S. Nejad (1998). Spray structures of Liquid Jets Atomized in Subsonic Crossflows, Journal of Propulsion Power, 14, 173-182. 